\title{
Study on Oxygen Supply Standard for Physical Health of Construction Personnel of High-Altitude Tunnels
}

\author{
Chun Guo ${ }^{1, *}$, Jianfeng $X u^{1}$, Mingnian Wang ${ }^{1}$, Tao Yan ${ }^{1}$, Lu Yang ${ }^{2}$ and Zhitao Sun ${ }^{1}$ \\ Received: 15 September 2015; Accepted: 16 December 2015; Published: 22 December 2015 \\ Academic Editor: Andrew Watterson \\ 1 Key Laboratory of Transportation Tunnel Engineering, Ministry of Education, \\ Southwest Jiaotong University, 111 Erhuan Rd, 610031 Chengdu, China; xujf@my.swjtu.edu.cn (J.X.); \\ mingnianw@163.com (M.W.); swjtuyt@163.com (T.Y.); sunzhitaovip@163.com (Z.S.) \\ 2 College of Foreign Languages, Southwest Jiaotong University, 111 Erhuan Rd, 610031 Chengdu, China; \\ yanglu@swjtu.edu.cn \\ * Correspondence: guochun@swjtu.edu.cn; Tel.: +86-028-8763-4386; Fax: +86-028-8760-0612
}

\begin{abstract}
The low atmospheric pressure and low oxygen content in high-altitude environment have great impacts on the functions of human body. Especially for the personnel engaged in complicated physical labor such as tunnel construction, high altitude can cause a series of adverse physiological reactions, which may result in multiple high-altitude diseases and even death in severe cases. Artificial oxygen supply is required to ensure health and safety of construction personnel in hypoxic environments. However, there are no provisions for oxygen supply standard for tunnel construction personnel in high-altitude areas in current tunnel construction specifications. As a result, this paper has theoretically studied the impacts of high-altitude environment on human bodies, analyzed the relationship between labor intensity and oxygen consumption in high-altitude areas and determined the critical oxygen-supply altitude values for tunnel construction based on two different standard evaluation systems, i.e., variation of air density and equivalent $\mathrm{PIO}_{2}$. In addition, it has finally determined the oxygen supply standard for construction personnel in high-altitude areas based on the relationship between construction labor intensity and oxygen consumption.
\end{abstract}

Keywords: high-altitude; oxygen supply; construction labor intensity; oxygen consumption; air density; equivalent $\mathrm{PIO}_{2}$

\section{Introduction}

With the rapid growth of China's economy, the scale of road construction becomes larger year by year [1]. More and more high-altitude tunnel construction works have been placed on the agenda. According to incomplete statistics, for the moment, there are totally eight super long tunnels with the altitude above $3000 \mathrm{~m}$ having been completed or under construction, and there are more than $10 \mathrm{such}$ tunnels under contemplation. The high-altitude tunnels currently completed and under construction in China, according to preliminary statistics, are listed in Table 1. 
Table 1. Statistics of completed and under-construction high-altitude tunnels in China.

\begin{tabular}{cccc}
\hline Number & Name of Tunnel & Length (m) & Portal Altitude (m) \\
\hline 1 & Dabanshan Tunnel & 1350 & 3792 \\
\hline 2 & Tielimaiti Tunnel & 1894 & 3220 \\
\hline 3 & Yuximolegai Tunnel & 1943 & 3200 \\
\hline 4 & Galongla Tunnel & 3350 & 3250 \\
\hline 5 & Bai Mang Snow Mountain Tunnel & 3951 & 4008 \\
\hline 6 & Zhegushan Tunnel & 4448 & 3400 \\
\hline 7 & Queershan Tunnel (under construction) & 7048 & 4300 \\
\hline 8 & Balangshan Tunnel (under construction) & 7954 & 3852 \\
\hline
\end{tabular}

According to related statistics, during construction of the tunnels of Qinghai-Tibet Railway during June-December 2001, as many as 36 cases of acute high altitude reaction syndrome [2] of construction personnel were reported. Among them, four cases happened at altitudes of $3000-4600 \mathrm{~m}$, accounting for $11.1 \%$; eight cases happened at altitudes of $4600-4800 \mathrm{~m}$, accounting for $22.2 \%$; and 24 cases happened at altitudes of $4800-5010 \mathrm{~m}$, accounting for $66.7 \%$.

Different from plain environment, high-altitude environment is characterized by low temperature, low atmospheric pressure and low content of oxygen. These differences have great physiological effects on the tunnel construction personnel, ranging from adverse physiological reactions [3] that may result in multiple high-altitude diseases to life risks in severe conditions. As a result, the safety of tunnel construction in high-altitude areas is significantly influenced. In particular, the low atmospheric pressure and oxygen content in high-altitude areas have enormous impacts on functions of human body.

Air oxygen content refers to the amount of oxygen molecules contained in air per unit volume, which decreases with the increase of altitude. In addition, atmospheric pressure (PB) also greatly influences functions of human body, this is because oxygen partial pressure $\left(\mathrm{PO}_{2}\right)$ [4] decreases with reduced $\mathrm{PB}$ while the water vapor pressure $\left(\mathrm{PH}_{2} \mathrm{O}\right)(47 \mathrm{mmHg})$ and $\mathrm{CO}_{2}$ pressure $\left(\mathrm{PCO}_{2}\right)(40 \mathrm{mmHg})$ in alveolus remain unchanged. If $\mathrm{PB}$ is $87 \mathrm{mmHg}$ at the high altitude of $15,000 \mathrm{~m}$, which is exactly equal to the sum of $\mathrm{PH}_{2} \mathrm{O}$ and $\mathrm{PCO}_{2}$ in alveolus, gas exchange cannot be conducted, even if pure $\mathrm{O}_{2}$ is supplied [5]. Therefore, the changes in $\mathrm{PO}_{2}$ and $\mathrm{PB}$ are important factors influencing human respiration and oxygen transfer in high-altitude areas. Refer to Table 2 for hypoxia responses [6] of human body at different altitudes. The equivalent oxygen concentration in Table 2 means that the mass of oxygen contained in altitude air per unit volume at local PB is same to the mass of certain concentration at the pressure of sea level.

Table 2. Hypoxia responses of human body at different altitudes.

\begin{tabular}{|c|c|c|c|c|c|}
\hline Altitude (m) & 0 & 1320 & $2400-3510$ & $3510-6440$ & $6440-10,860$ \\
\hline $\mathrm{PO}_{2}(\mathrm{mmHg})$ & 159 & $<137$ & $121-106$ & $106-76$ & $76-46$ \\
\hline $\begin{array}{l}\text { Equivalent PB } \\
\text { (atm) }\end{array}$ & 1 & 0.86 & $0.76-0.67$ & $0.67-0.48$ & $<0.48$ \\
\hline $\begin{array}{c}\text { Hypoxia } \\
\text { symptoms of } \\
\text { human body } \\
\text { [7] }\end{array}$ & Normal & $\begin{array}{l}\text { Histocytes are } \\
\text { in the hypoxia } \\
\text { environment } \\
\text { and slight } \\
\text { symptoms are } \\
\text { observed. }\end{array}$ & $\begin{array}{c}\text { Deepened respiration, } \\
\text { headache, quickened } \\
\text { pulse and elevated } \\
\text { blood pressure are } \\
\text { observed. } \\
\text { Coordinating } \\
\text { functions of the body } \\
\text { are degenerating and } \\
\text { sleeping problems } \\
\text { occur. }\end{array}$ & $\begin{array}{c}\text { Fatigue, } \\
\text { depression, } \\
\text { attention } \\
\text { deficit, } \\
\text { dizziness and } \\
\text { disorientation } \\
\text { occur. }\end{array}$ & $\begin{array}{l}\text { The symptoms of } \\
\text { tinnitus, blurred } \\
\text { vision, nausea and } \\
\text { vomiting are } \\
\text { observed. The body } \\
\text { cannot move } \\
\text { voluntarily. The } \\
\text { patient can no longer } \\
\text { speak and will become } \\
\text { unconscious quickly. }\end{array}$ \\
\hline
\end{tabular}


It can be concluded that physical health of tunnel construction personnel in high altitude areas can be greatly impacted by air oxygen content. Therefore, artificial oxygen supply is of significant importance to ensure health and safety of construction personnel in hypoxic environment [8]. However, provisions for oxygen supply standard for tunnel construction personnel at altitude are dismissed. We hope our study will contribute to the working health and life security of high altitude workers, especially those are native plainsmen.

\section{Related Diseases about Altitude Hypoxia and Human Adjustment to Altitude}

The amount of oxygen inhaled by tunnel construction personnel is directly influenced by oxygen concentration in the air. When air $\mathrm{PO}_{2}$ decreases, human respiration will be effected. The greater the oxygen concentration decreases, the more difficult respiration becomes. Human body will become hypoxic when oxygen concentration decreases to a certain degree, then working capacity will be reduced and various symptoms will occur.

Table 3 describes the relationship between hypoxia symptoms of construction personnel and air oxygen concentration [9].

Table 3. Relationship between acute hypoxia symptoms of construction personnel and oxygen concentration.

\begin{tabular}{cc}
\hline $\mathbf{P O}_{\mathbf{2}} \mathbf{( \mathbf { m m H g } )}$ & Main Symptoms \\
\hline 129 & $\begin{array}{c}\text { No symptoms are observed when staying still. In movement, respiration } \\
\text { frequency and resistance increase. Heart rate increases as well. }\end{array}$ \\
\hline 121 & $\begin{array}{c}\text { Respiration and heart rate increase. Dizziness and tinnitus occur. } \\
\text { Judging capability is compromised and labor ability is lost. }\end{array}$ \\
\hline $76-91$ & Awareness and judgment become abnormal. Long-term exposure can be \\
& life threatening. \\
\hline & $\begin{array}{c}\text { The symptoms of loss of consciousness and respiratory arrest occur. } \\
\text { Heartbeat can only sustain for a short time and death will result without } \\
\text { timely emergency treatment. }\end{array}$ \\
\hline
\end{tabular}

It is easy to see that severe lack of oxygen can imminently threaten the life of construction personnel.

When workers enter high altitude, air pressure declines and air density decreases. The increase of pulmonary ventilation is an important physiologic compensation for low $\mathrm{PO}_{2}$ of inhaled gas $\left(\mathrm{PIO}_{2}\right)$. As a result, constructors consume more volume of oxygen and output more $\mathrm{CO}_{2}$. Adaptive hyperventilation leads to a low $\mathrm{PCO}_{2}$ of artery blood. The blood tends to be alkaline and hypocarbia may occur. At the same time, the sensitivity of respiratory centers in brain to $\mathrm{CO}_{2}$ arises to decline the reaction threshold. This helps keep a relatively high level of pulmonary ventilation as the mechanism adjustment to hypoxia but may also result in respiratory alkalosis, which is not in favor of altitude acclimatization [10].

One typical disease caused by hypoxia is called acute mountain sickness (AMS), which refers to a series of acute hypoxia stress reaction of sea-level humans who have not established acclimatization of environmental adaptation mechanisms. The clinical manifestations of AMS are headache, hyperpnea, exertional dyspnea, cyanosis, anorexia, and abdominal distention [11].

Another disease named high-altitude pulmonary edema (HAPE) might be a greater threat to the health of construction workers. HAPE is a form of non-cardiogenic pulmonary edema that typically occurs in people who engage in vigorous physical activity without prior training. The attack of HAPE occurs quickly, does not cause fever, but does have premonitory symptoms such as headache, palpitation, insomnia, anorexia and nausea. The disease develops rapidly and requires active treatment. Otherwise, delay in therapy may result the death of patients [12].

What needs to be underlined is that the occurrence of HAPE at an altitude $<2500 \mathrm{~m}$ is probably underestimated. André LG reported a series of 52 patients admitted for HAPE occurring at moderate 
altitude (1400 to $2400 \mathrm{~m}$ ) over a nine-year period in a community hospital in the French Alps. They stated that HAPE patients are likely to be young, vacationing men, with no history of prior disease. Caution should be considered in the case of future high altitude travel [13].

High altitude cerebral edema (HACE) is usually thought to be the deuteropathy of AMS and HAPE. HACE is less common than AMS or HAPE but more mortal compared with the two diseases. It is known that the brain is the most oxygen-consuming organ of the human body when at rest. When people are exposed in low oxygen environment, human body will make adjustment measures to offset the influence of low $\mathrm{PIO}_{2}$. However, in the condition of urgent hypoxia, the brain blood circuit systems begin to have trouble and metabolic disorders happen. The patients of HACE firstly show disturbance of consciousness, then develop to deep coma, mental changes, clouding of consciousness and ataxia to some extent. Currently, the lowest recorded altitude of HACE attack is $2100 \mathrm{~m}$, according to Dickinson. Without universal criteria for the definition and diagnoses, research on its epidemiology is also very limited. As a result, the actual morbidity of HACE is unclear [14].

Self $e$ t al. investigated possible physiological determinants of variability in hypoxia tolerance in subjects given a five-minute normobaric exposure to $7620 \mathrm{~m}$ equivalent. He reported that subjects with large total lung diffusion capacities for $\mathrm{O}_{2}$, those with the highest end-alveolar $\mathrm{PO}_{2}$ and the lowest mixed venous partial pressure $\left(\mathrm{PvO}_{2}\right)$ at the end of the 5-min exposure, and those who maintained an $\mathrm{O}_{2}$ consumption rate that exceeded their resting levels, had the smallest declines in hemoglobin saturation [15].

A complex series of adaptive mechanisms follows the human being's exposure to high altitude and the consequent hypobarism. However, the work of actual adaptive mechanisms depends on the rate of ascent and the altitude reached. If the mechanisms work, physiologic compensatory reaction will occur in human body and the acclimatization is successful. As to human beings who are exposed to high altitude, hypoxia stimulates the artery chemical sense receptors, which enhances ventilation through neuroregulation. Hyperventilation is necessary for high altitude adjustment. Hyperventilation replenishes more fresh inspiratory gas for pulmonary alveoli [16]. As a result, the $\mathrm{PO}_{2}$ at the interface between gas and blood increases and improve human ventilation.

In other words, the health and safety of construction workers faces severe threats from hypoxia. To protect human health at high altitudes and push the advance of altitude construction, oxygen supply is indispensable. However, at what altitude should oxygen supply start? We will introduce two different calculation methods to determine the specific altitudes that oxygen supply should start in the following section.

\section{Determination of Critical Oxygen-Supply Altitude for Construction Based on Changes in Air Density}

Based on the influences of high-altitude environment on functions of human body, it can be seen that the oxidation capability is certain for some specific labor intensity of human body. As a result, the following assumptions have been made in this study:

(1) The amount of oxygen molecules required for the human body at set labor intensity is known.

(2) Volume concentration of oxygen does not change with the increase of altitude.

(3) Except altitude, all other factors are the same.

Considering that air densities and oxygen contents of low- and high-altitude areas are different and based on the above-mentioned assumptions, the amount of oxygen can be used as the basic value to obtain the maximum altitude that non-residents of high-altitude areas engaged in physical labor can adapt to $i$. The following equation can be established based on analyses:

Sea-level oxygen density $\times$ limit oxygen concentration $\times$ unit volume $=$ unit volume $\times$ standard oxygen concentration $\times$ oxygen density at altitude

It is known that sea-level oxygen density is $1.429 \mathrm{~kg} / \mathrm{m}^{3}$ and sea-level air density is $1.29 \mathrm{~kg} / \mathrm{m}^{3}$. In low-altitude areas, the oxygen concentration possibly causing hypoxia of human body is 
$16 \%$, while that possibly causing severe oxygen deficit is $12 \%$. Theoretically, standard oxygen concentration is $21 \%$. The relationships between altitude and air density, between density and pressure, and the above-mentioned equation are combined. Considering that densities of air and oxygen change in direct proportion, the critical oxygen-supply altitude that satisfies the requirements for both labor ability and life support of construction personnel can be determined.

It is worth noting that heat emission during tunnel construction may increase the temperature in certain areas inside tunnel. According to Dalton's Law of Partial Pressure, the air pressure in these areas will decline further due to the unchangeable volume in the tunnel. However, as to the input of fresh air and the heat exchange between air and rock in the tunnel, the temperature in long tunnels will cool down at places about $500 \mathrm{~m}$ away from construction face. The influence of temperature increase in long tunnels is very limited. However, the hypoxia situation in partial regions inside tunnel may be greater and therefore warrants caution and treatment to eliminate the passive effects on the working oxygen supply for workers.

\subsection{Critical Oxygen-Supply Altitude Based on Labor Ability of Construction Personnel}

Taking account of the influences of changes in air density listed in Table 2, we know that if the equivalent oxygen concentration is not less than $16 \%$, construction workers still maintain working ability. Naturally, we can take use of the relationship among gas density, altitude and gas pressure to calculate the critical altitude. The critical oxygen-supply altitude based on labor ability of construction personnel is determined as follows:

$$
1.429 \times 16 \% \times 1=\rho_{\text {oh }} \times 21 \% \times 1 \Rightarrow \rho_{\text {oh }}=1.086 \mathrm{~kg} / \mathrm{m}^{3}
$$

where 1.429 (unit: $\mathrm{kg} / \mathrm{m}^{3}$ ) is sea-level oxygen density, $16 \%$ stands for the volume concentration of oxygen, 1 (unit: L) is the volume of oxygen, $21 \%$ is the volume fraction of oxygen, and $\rho_{\mathrm{oh}}$ (unit: $\mathrm{kg} / \mathrm{m}^{3}$ ) is the oxygen density at certain altitude.

$$
\frac{\rho_{\text {oh }}}{\rho_{\text {osl }}}=\frac{\rho_{\text {ah }}}{\rho_{\text {asl }}} \Rightarrow \rho_{\text {ah }}=\frac{\rho_{\text {oh }} \rho_{\text {asl }}}{\rho_{\text {osl }}}=\frac{1.806 \times 1.29}{1.429}=0.982 \mathrm{~kg} / \mathrm{m}^{3}[17]
$$

where $\rho_{\text {oh }}$ (unit: $\mathrm{kg} / \mathrm{m}^{3}$ ) stands for the oxygen density at the altitude of $\mathrm{h}$ (unit: $\mathrm{m}$ ), $\rho_{\text {osl }}$ (unit: $\mathrm{kg} / \mathrm{m}^{3}$ ) is the oxygen density at sea-level, $\rho_{a h}\left(\right.$ unit: $\mathrm{kg} / \mathrm{m}^{3}$ ) means air density at the altitude of $\mathrm{h}$ (unit: $\mathrm{m}$ ), and $\rho_{\text {asl }}$ (unit: $\mathrm{kg} / \mathrm{m}^{3}$ ) is air density at sea-level.

$$
\frac{\rho_{a}}{\rho_{0}}=\frac{P_{a}}{P_{0}} \Rightarrow P_{a}=\frac{\rho_{a} P_{0}}{\rho_{0}}=\frac{0.982 \times 101.325}{1.29}=76.96 \mathrm{kPa}[17]
$$

where $\mathrm{P}_{\mathrm{a}}$ (unit: $\mathrm{kPa}$ ) stands for the air pressure at the altitude of $\mathrm{h}$ (unit: $\mathrm{m}$ ), $\mathrm{P}_{\mathrm{o}}$ (unit: $\mathrm{kPa}$ ) is the $\mathrm{PO}_{2}$ at sea-level, $\rho_{\mathrm{a}}$ (unit: $\mathrm{kg} / \mathrm{m}^{3}$ ) means air density at the altitude of $\mathrm{h}$, and $\rho_{\mathrm{o}}\left(\right.$ unit: $\mathrm{kg} / \mathrm{m}^{3}$ ) is oxygen density at sea-level (unit: $\mathrm{m}$ ).

$$
P_{a}=101.325 \times\left(1-\frac{h}{44329}\right)^{5.255876} \Rightarrow h \approx 2500 m[18]
$$

where $\mathrm{h}$ is the elevation height (unit: $\mathrm{m}$ ) and $\mathrm{P}_{\mathrm{a}}$ (unit: $\mathrm{kPa}$ ) stands for the air partial pressure at the altitude of $\mathrm{h}$ (unit: $\mathrm{m}$ ), while 101.325 (unit: $\mathrm{kPa}$ ) is the air pressure at sea-level.

\subsection{Critical Oxygen-Supply Altitude Based on Life Support of Construction Personnel}

Similarly, the critical oxygen-supply altitude based on life support of construction personnel is:

$$
1.429 \times 12 \% \times 1=\rho_{\text {oh }} \times 21 \% \times 1 \Rightarrow \rho_{\text {oh }}=0.817 \mathrm{~kg} / \mathrm{m}^{3}
$$


where 1.429 (unit: $\mathrm{kg} / \mathrm{m}^{3}$ ) is sea-level oxygen density, 12\% stands for the volume concentration of oxygen, 1 (unit: L) is the volume of oxygen, $21 \%$ is the volume fraction of oxygen, and $\rho_{\mathrm{oh}}$ (unit: $\mathrm{kg} / \mathrm{m}^{3}$ ) is the oxygen density at certain altitude.

$$
\frac{\rho_{\text {oh }}}{\rho_{\text {osl }}}=\frac{\rho_{\text {ah }}}{\rho_{\text {asl }}} \Rightarrow \rho_{\text {ah }}=\frac{0.817 \times 1.29}{1.429}=0.73 \mathrm{~kg} / \mathrm{m}^{3}
$$

where $\rho_{\text {oh }}$ (unit: $\mathrm{kg} / \mathrm{m}^{3}$ ) stands for the oxygen density at the altitude of $\mathrm{h}$ (unit: $\mathrm{m}$ ), $\rho_{\text {osl }}$ (unit: $\mathrm{kg} / \mathrm{m}^{3}$ ) is the oxygen density at sea-level, $\rho_{\mathrm{ah}}\left(\right.$ unit: $\mathrm{kg} / \mathrm{m}^{3}$ ) means air density at the altitude of $\mathrm{h}$ (unit: $\mathrm{m}$ ), and $\rho_{\text {asl }}\left(\right.$ unit: $\mathrm{kg} / \mathrm{m}^{3}$ ) is air density at sea-level.

$$
\frac{\rho_{a}}{\rho_{0}}=\frac{P_{a}}{P_{0}} \Rightarrow P_{a}=\frac{\rho_{a} P_{0}}{\rho_{0}}=\frac{0.73 \times 101.325}{1.29}=57.2 \mathrm{kPa}
$$

where $\mathrm{P}_{\mathrm{a}}$ (unit: $\mathrm{Pa}$ ) stands for the air pressure at the altitude of $\mathrm{h}$ (unit: $\mathrm{m}$ ), $\mathrm{P}_{\mathrm{o}}$ (unit: $\mathrm{kPa}$ ) is the $\mathrm{PO}_{2}$ at sea-level (unit: $\mathrm{m}$ ), $\rho_{\mathrm{a}}$ (unit: $\mathrm{kg} / \mathrm{m}^{3}$ ) means air density at the altitude of $\mathrm{h}$, and $\rho_{\mathrm{o}}$ (unit: $\mathrm{kg} / \mathrm{m}^{3}$ ) is oxygen density at sea-level (unit: $\mathrm{m}$ ).

$$
P_{a}=101.325 \times\left(1-\frac{h}{44329}\right)^{5.255876} \Rightarrow h \approx 4600 m
$$

where $\mathrm{h}$ is the elevation height (unit: $\mathrm{m}$ ), $\mathrm{P}_{\mathrm{a}}$ (unit: $\mathrm{kPa}$ ) stands for the air partial pressure at the altitude of $\mathrm{h}$ (unit: $\mathrm{m}$ ) and 101.325 (unit: $\mathrm{kPa}$ ) is the air pressure at sea-level.

By analyzing the relationship between two critical oxygen concentrations and corresponding altitudes, the possibilities that construction personnel will suffer hypoxia at altitudes $>2500 \mathrm{~m}$ and severe hypoxia will occur when altitude exceeds $4600 \mathrm{~m}$ have been theoretically predicted.

In Discussions on Labor Sanitation and Protection in High-altitude Areas [19], it is mentioned that when altitude is below $3000 \mathrm{~m}$, the degree of blood oxygen saturation concentration of human body is usually above $90 \%$. In this case, people will not develop hypoxia symptoms. Only slight increase of respiration frequency and heart rate is observed, which is called "the range with no obvious change". At altitudes of 3000 4000 m, approximately one-third to one-fourth of people show inadaptability to high altitudes, when symptoms of quickened respiration and heart rate and hypoxia of organs occur. This range is called the "compensatory range". At altitudes of $4500 \sim 6000 \mathrm{~m}$, dysfunction of human body may occur, and this range is called the "dysfunction range". At altitudes above $6000 \mathrm{~m}$, hypoxia is aggravated, with the symptoms of collapse and coma. In this case, blood oxygen saturation concentration has decreased to below $70 \%$. This range is usually called the "highly dangerous altitudes".

According to the above-mentioned statements and analyses on statistics of high-altitude syndromes of construction personnel working in high-altitude areas, the critical oxygen-supply altitude at which hypoxia may occur in the personnel is $2500 \mathrm{~m}$, while the altitude at which severe hypoxia responses may occur is $4500 \mathrm{~m}$.

\section{Calculation Method for Critical Oxygen-Supply Altitude Based on Equivalent $\mathbf{P I O}_{2}$}

The oxygen in the air is the only oxygen source for human body without auxiliary oxygen-supply measures.

$\mathrm{PB}$ and oxygen concentration are the direct factors for determining $\mathrm{PO}_{2}$. Their relationship can be expressed with the following equation: $\mathrm{PO}_{2}=\mathrm{PB} \times$ atmospheric oxygen concentration. In normal condition, volume concentration of oxygen in the air is $21 \%$. Theoretically, it does not change along with altitudes. Therefore, $\mathrm{PO}_{2}$ mainly depends on atmospheric pressure. The higher the atmospheric pressure is, the higher the oxygen partial pressure will be. As the water vapor in the respiratory tract is fully saturated at normal body temperature and the $\mathrm{PH}_{2} \mathrm{O}$ in the trachea is $47 \mathrm{mmHg}, \mathrm{PIO}_{2}$ is lower than in the atmosphere. During each respiration, only some alveolar air is exchanged, while the 
oxygen in alveolar continues to disperse into alveolar capillaries [20-22]. Therefore, the oxygen partial pressure of alveolar air $\left(\mathrm{PAO}_{2}\right)$ is about one-third lower than the $\mathrm{PIO}_{2}$ in the trachea. The oxygen contained in alveolar air can be dispersed into the blood. In addition, $\mathrm{PAO}_{2}$ is also related to alveolar ventilation and oxygen consumption of the body. When alveolar ventilation decreases or oxygen consumption of the body increases, $\mathrm{PAO}_{2}$ is reduced and vice versa.

$\mathrm{PAO}_{2}=\left(\mathrm{PB}-\mathrm{PH}_{2} \mathrm{O}\right) \times \mathrm{FiO}_{2}-1.25 \times \mathrm{PCO}_{2}$.

$\mathrm{FiO}_{2}$ stands for the fraction of inspired oxygen.

According to proceeding equation, we can calculate the $\mathrm{PAO}_{2}$ at different altitudes and the results is shown in Table 4.

Table 4. Changes in atmospheric pressure, atmospheric oxygen partial pressure, oxygen partial pressure of inhaled gas and alveolar oxygen partial pressure at different altitudes.

\begin{tabular}{ccccc}
\hline Altitude $(\mathbf{m})$ & $\mathbf{P B}(\mathbf{m m H g})$ & $\mathbf{P O}_{\mathbf{2}} \mathbf{( \mathbf { m m H g } )}$ & $\mathbf{P I O}_{\mathbf{2}} \mathbf{( \mathbf { m m H g } )}$ & $\mathbf{P A O}_{\mathbf{2 n}} \mathbf{( \mathbf { m m H } )}$ \\
\hline 0 & 760 & 159 & 149 & 105 \\
1000 & 674 & 141 & 131 & 90 \\
\hline 2000 & 596 & 125 & 115 & 70 \\
\hline 3000 & 530 & 110 & 100 & 62 \\
4000 & 460 & 98 & 87 & 50 \\
\hline 5000 & 405 & 85 & 74 & 45 \\
6000 & 355 & 74 & 64 & 40 \\
\hline 7000 & 310 & 65 & 55 & 35 \\
\hline 8000 & 270 & 56 & 47 & 30 \\
\hline
\end{tabular}

$\mathrm{PIO}_{2}$ is a main factor for oxygen to influence human body. Decreased oxygen concentration and $\mathrm{PB}$ will result in decreased $\mathrm{PO}_{2}$ and thus lead to hypoxia of human body. In high-altitude areas, equivalent oxygen concentration is relatively low and $\mathrm{PIO}_{2}$ decreases with atmospheric $\mathrm{PO}_{2}$. To determine the oxygen deficit standard more conveniently, it is more intuitive to measure the degree of oxygen deficit with altitude instead of oxygen concentration in high-altitude areas. Therefore, oxygen concentration can be converted into altitude to indicate content of oxygen.

Calculation formula for PB at the altitude below 11,000 $\mathrm{m}$ is shown as Equation (1):

$$
P B=101.325 \times\left(1-\frac{h}{44329}\right)^{5.255876}
$$

The unit of PB in Equation (1) is $\mathrm{kPa}$ and $\mathrm{h}$ stands for altitude height (unit: $\mathrm{m}$ ).

The common calculation formula for $\mathrm{PIO}_{2}$ is shown as Equation (2):

$$
\mathrm{PIO}_{2}=\mathrm{FiO}_{2}\left(\mathrm{~PB}-\mathrm{PH} \mathrm{H}_{2} \mathrm{O}\right)
$$

The unit of $\mathrm{PIO}_{2}$ in Equation (2) is $\mathrm{kPa}$ and the value of $\mathrm{PH}_{2} \mathrm{O}$ is $6.27 \mathrm{kPa}$.

By combining the above equations, it is concluded that the air with a given oxygen concentration at a specified altitude can be related to the air with a normal oxygen concentration $(21 \%)$ at a specified altitude. Refer to Equation (3), where the altitude is $\mathrm{h}_{1}$, oxygen concentration is $\mathrm{FiO}_{2}$ and equivalent altitude is $\mathrm{h}_{2}$ :

$$
\boldsymbol{h}_{2}=\mathbf{a} \times\left\{1-\sqrt[b]{\frac{\boldsymbol{F i O}_{2}\left[101.325\left(1-\boldsymbol{h}_{1} / \mathbf{a}\right)^{b}-6.27\right]}{21.217455}}\right\}
$$

where, $\mathrm{a}=44,329$ and $\mathrm{b}=5.255876$, $\mathrm{a}$ and $\mathrm{b}$ are both constants. 


\section{Determination of Critical Oxygen-Supply Altitude for Construction Based on Equivalent $\mathrm{PIO}_{2}$}

Considering the impact of equivalent $\mathrm{PIO}_{2}$, Equation (3) is adopted for calculation, and the critical oxygen-supply altitude for construction personnel is obtained as follows [23]:

\subsection{Critical Oxygen-Supply Altitude Based on Labor Ability of Personnel}

Critical oxygen-supply altitude based on labor ability of personnel:

$$
\begin{aligned}
& \boldsymbol{h}_{2}=\mathbf{a} \times\left\{1-\sqrt[b]{\left.\frac{\mathbf{F i O}_{2}\left[101.325\left(1-\boldsymbol{h}_{1} / \mathbf{a}\right)^{b}-6.27\right]}{21.217455}\right\}}\right\} \\
& =44329 \times\left\{1-\sqrt[5.255876]{\frac{0.16 \times\left[101.325(1-0 / 44329)^{5.255876}-6.27\right]}{21.217455}}\right\} \\
& \approx 2700 \mathrm{~m}
\end{aligned}
$$

\subsection{Critical Oxygen-Supply Altitude Based on Life Support of Personnel}

Critical oxygen-supply altitude based on life support of personnel:

$$
\begin{aligned}
& \boldsymbol{h}_{2}=\mathbf{a} \times\left\{1-\sqrt[b]{\left.\frac{\boldsymbol{F i O}_{2}\left[101.325\left(1-\boldsymbol{h}_{1} / \mathbf{a}\right)^{\boldsymbol{b}}-6.27\right]}{21.217455}\right\}}\right\} \\
& =44329 \times\left\{1-\sqrt[5.255876]{\frac{0.12 \times\left[101.325(1-0 / 44329)^{5.255876}-6.27\right]}{21.217455}}\right\} \\
& \approx 4950 \mathrm{~m}
\end{aligned}
$$

Analyses and calculations are conducted on two critical oxygen concentrations based on the principle of equivalent $\mathrm{PIO}_{2}$. In theory, the possibilities that construction personnel will suffer hypoxia at altitudes $>2700 \mathrm{~m}$ and severe hypoxia will occur when altitude exceeds $4950 \mathrm{~m}$ have been theoretically predicted. For the purpose of guaranteeing personal safety, the altitude for oxygen deficit is determined rather conservatively, i.e., the critical oxygen-supply altitude for possible hypoxia responses is $2500 \mathrm{~m}$, while the critical oxygen-supply altitude for severe hypoxia responses is $4500 \mathrm{~m}$.

Based on calculations of above-mentioned critical oxygen-supply altitudes, it is finally decided that the critical altitude at which oxygen must be supplied to construction personnel is $4500 \mathrm{~m}$, while that at which labor ability of construction personnel shall be considered is $2500 \mathrm{~m}$.

\section{Oxygen Supply for Construction at Different Altitudes}

Although the starting oxygen supply heights are decided in previous sections, the oxygen supply criteria for different altitudes are undetermined. By supplying oxygen, the $\mathrm{PIO}_{2}$ at different altitudes can reach the level of low-altitude areas. The following is the equivalent oxygen supply theory to calculate the needed oxygen in per unit volume of air at altitude:

$$
\mathrm{PIO}_{2}=\left(\mathrm{PB}-\mathrm{PH}_{2} \mathrm{O}\right) \times \mathrm{FiO}_{2}
$$

According to Equation (4) and the values of PB in Table 4, the oxygen supply for increasing oxygen contents at higher altitudes to the level of sea level can be calculated [24], as shown in Table 5 . $\mathrm{FiO}_{2}$ increases with the rise of altitudes. 
Table 5. $\mathrm{FIO}_{2}$ required for maintaining sea-level $\mathrm{PO}_{2}$.

\begin{tabular}{cccccccc}
\hline Altitude (m) & $\mathbf{1 0 0 0}$ & $\mathbf{2 0 0 0}$ & $\mathbf{3 0 0 0}$ & $\mathbf{4 0 0 0}$ & $\mathbf{5 0 0 0}$ & $\mathbf{6 0 0 0}$ & $\mathbf{7 0 0 0}$ \\
\hline $\mathrm{FiO}_{2}(\%)$ & 23.76 & 27.14 & 30.85 & 36.08 & 41.32 & 48.38 & 56.65 \\
\hline
\end{tabular}

Compared with the $\mathrm{FiO}_{2}$ of sea level (21\%), the increase of $\mathrm{FiO}_{2}$ with altitude increase is more and more obvious. For example, the $\mathrm{FiO}_{2}$ difference between sea level and the altitude of $1000 \mathrm{~m}$ is only 2.76 percentage points, but the difference increase to 7.08 percentage points between the altitude of $5000 \mathrm{~m}$ and $6000 \mathrm{~m}$. The reason is the accelerating increase of air density difference at higher altitude.

\section{Relationship between Labor Intensity in Tunnel Construction and Oxygen Consumption in High-Altitude Areas}

The intensity of short-interval labor is usually greater than that of long-interval labor. If intensity of individual labor were classified as different labor intensity grades based on energy consumption, the grade values would mean the rank in intensity classification would be higher than expected. Therefore, this method is seldom adopted presently. To further determine the relationship between types of work and oxygen demand and consumption as well as determine the oxygen-supply plan for tunnel construction personnel in high-altitude areas, oxygen consumption is thus taken as the criterion for classifying labor grade [25,26].

Based on classification on intensity of physical work of China [27] and the oxygen consumption and amount of inspired air for each grade of labor intensity, the volumes of oxygen needed by human body at the PB of different altitudes are estimated and shown in Table 6 . The grades of labor intensity of several main procedures in tunnel construction and the oxygen consumption of sea level are determined, as shown in Table 7.

Table 6. Minimum oxygen consumption under different labor intensities at different altitudes (L/min).

\begin{tabular}{ccccccc}
\hline Labor Intensity & $\mathbf{0 ~} \mathbf{~}$ & $\mathbf{1 0 0 0} \mathbf{~}$ & $\mathbf{2 0 0 0} \mathbf{~}$ & $\mathbf{3 0 0 0} \mathbf{~}$ & $\mathbf{4 0 0 0} \mathbf{~}$ & $\mathbf{5 0 0 0} \mathbf{~}$ \\
\hline Very light & $<0.5$ & $<0.6$ & $<0.6$ & $<0.7$ & $<0.8$ & $<0.9$ \\
\hline Light & 0.5 & 0.6 & 0.6 & 0.7 & 0.8 & 0.9 \\
\hline Moderate & 1 & 1.1 & 1.3 & 1.4 & 1.6 & 1.8 \\
\hline Heavy & 1.5 & 1.7 & 1.9 & 2.2 & 2.4 & 2.7 \\
\hline Very heavy & 2 & 2.3 & 2.5 & 2.9 & 3.2 & 3.6 \\
\hline Extremely heavy & 2.5 & 2.8 & 3.2 & 3.6 & 4 & 4.5 \\
\hline
\end{tabular}

Table 7. Grades of labor intensity of main procedures in tunnel construction and oxygen consumption at sea level.

\begin{tabular}{ccc}
\hline Procedure & Grade of Labor Intensity & Oxygen Consumption (L/min) \\
\hline Drilling and blasting & Very heavy labor & $2.0-2.5$ \\
\hline Shotcrete & Heavy labor & $1.5-2.0$ \\
\hline Formwork lining & Heavy labor & $1.5-2.0$ \\
\hline Paving waterproof board & Moderate labor & $1.0-1.5$ \\
\hline Slag loading & Moderate labor & $1.0-1.5$ \\
\hline Slag tapping & Light labor & $0.5-1.0$ \\
\hline
\end{tabular}

Air volume expands and density decreases at an elevated altitude, which results in decrease in oxygen content in the air. As the amount of oxygen needed by human body is constant, the volumetric oxygen consumption of human body at local altitude can be obtained via mass conversion. 
Take the Balangshan Tunnel under construction as an example: The altitude of the tunnel is about $4000 \mathrm{~m}$, where air density is $0.802 \mathrm{~kg} / \mathrm{m}^{3}$, approximately $62 \%$ of the air density at sea level. As oxygen varies in direct proportion with air, oxygen content in the air is also $62 \%$ of that at sea level. New grades of labor intensity and oxygen consumption $[28,29]$ are calculated at local PB via mass transformation, as shown in Table 8.

Table 8. Grade of labor intensity and oxygen consumption at the altitude of $4000 \mathrm{~m}$.

\begin{tabular}{ccc}
\hline Procedure & Grade of Labor Intensity & Oxygen Consumption (L/min) \\
\hline Drilling and blasting & Extremely heavy labor & $3.2-4$ \\
\hline Shotcrete & Extremely heavy labor & $2.4-3.2$ \\
\hline Formwork lining & Extremely heavy labor & $2.4-3.2$ \\
\hline Paving waterproof board & Very heavy labor & $1.6-2.4$ \\
\hline Slag loading & Very heavy labor & $1.6-2.4$ \\
\hline Slag tapping & Heavy labor & $0.8-1.6$ \\
\hline
\end{tabular}

By analyzing the relationship between the grades of labor intensity of main procedures in tunnel construction and oxygen consumption at sea level, it can be seen that labor intensity and oxygen consumption increase in a gradual but significant manner at elevated altitudes.

\section{Determination of Oxygen-Supply Standard for Tunnel Construction Personnel in High-Altitude Areas}

It is usually believed that the volumetric percentage of oxygen in the air is constant in both high- and low-altitude areas. However, air density and oxygen density decrease at higher altitudes, resulting in decrease in oxygen content of the same volume. When people are engaged in manual work, the amount of oxygen needed for energy consumption will be constant if labor intensity is unchanged. In Ventilation and Oxygen Consumption Rate [30], it is believed that oxygen consumption of human body is $4.5 \mathrm{~mL}$ per $100 \mathrm{~mL}$ of ventilation. On this basis, the ventilation for different grades of labor intensity of human body at different altitudes can be estimated, as shown in Table 9.

Table 9. Minimum ventilation of human body under different labor intensities at different altitudes $(\mathrm{L} / \mathrm{min})$.

\begin{tabular}{ccccccc}
\hline Labor Intensity & $\mathbf{0 ~} \mathbf{~}$ & $\mathbf{1 0 0 0} \mathbf{~}$ & $\mathbf{2 0 0 0} \mathbf{~}$ & $\mathbf{3 0 0 0} \mathbf{~}$ & $\mathbf{4 0 0 0} \mathbf{~ m}$ & $\mathbf{5 0 0 0} \mathbf{~ m}$ \\
\hline Very light & $<11.1$ & $<12.5$ & $<14.2$ & $<16.1$ & $<17.9$ & $<20.0$ \\
\hline Light & 11.1 & 12.5 & 14.2 & 16.1 & 17.9 & 20.0 \\
\hline Moderate & 22.2 & 25.1 & 28.3 & 32.2 & 35.8 & 39.9 \\
\hline Heavy & 33.3 & 37.6 & 42.5 & 48.3 & 53.7 & 59.9 \\
\hline Very heavy & 44.4 & 50.1 & 56.6 & 64.4 & 71.6 & 79.9 \\
\hline Extremely heavy & 55.6 & 62.6 & 70.8 & 80.5 & 89.5 & 99.8 \\
\hline
\end{tabular}

Usually, ventilation of a human body not engaged in work is about $10 \mathrm{~L} / \mathrm{min}$, and maximum ventilation range is $70 \sim 120 \mathrm{~L} / \mathrm{min}$. To protect laborers' health, the conservative value of $70 \mathrm{~L} / \mathrm{min}$ is adopted as the maximum ventilation for work [31]. For the purpose of improving working efficiency and based on the ventilation values given in the table, it is suggested that extremely heavy labor not be conducted at the altitude of $3000 \mathrm{~m}$ or above and very heavy labor not be conducted at the altitude of $4000 \mathrm{~m}$ or above, at which moderate or lighter labor is recommended.

On the basis of relevant studies, it has been decided that the oxygen-supply altitude for guaranteeing labor ability of construction personnel is $2500 \mathrm{~m}$. By considering classification of labor 
intensity and minimum oxygen consumption under different labor intensities at different altitudes given in Table 6, the oxygen-supply standard based on labor ability of personnel can be determined, as shown in Table 10.

Table 10. Oxygen-supply standard based on labor ability of construction personnel.

\begin{tabular}{ccccccccc}
\hline \multirow{2}{*}{ Labor Intensity } & \multicolumn{7}{c}{ Oxygen Supply (L/min) } \\
\cline { 2 - 10 } & $\mathbf{2 5 0 0} \mathbf{~}$ & $\mathbf{3 0 0 0} \mathbf{~}$ & $\mathbf{3 5 0 0} \mathbf{~}$ & $\mathbf{4 0 0 0} \mathbf{~}$ & $\mathbf{4 5 0 0} \mathbf{~}$ & $\mathbf{5 0 0 0} \mathbf{~ m}$ & $\mathbf{5 5 0 0} \mathbf{~ m}$ & $\mathbf{6 0 0 0} \mathbf{~ m}$ \\
\hline Very light & 0 & 0.04 & 0.09 & 0.14 & 0.20 & 0.26 & 0.32 & 0.40 \\
\hline Light & 0 & 0.09 & 0.18 & 0.29 & 0.40 & 0.52 & 0.65 & 0.79 \\
\hline Moderate & 0 & 0.13 & 0.28 & 0.43 & 0.60 & 0.78 & 0.97 & 1.19 \\
\hline Heavy & 0 & 0.18 & 0.37 & 0.57 & 0.80 & 1.04 & 1.30 & 1.58 \\
\hline Very heavy & 0 & 0.22 & 0.46 & 0.72 & 1.00 & 1.30 & 1.62 & 1.98 \\
\hline Extremely heavy & 0 & 0.27 & 0.55 & 0.86 & 1.19 & 1.56 & 1.95 & 2.37 \\
\hline
\end{tabular}

Based on relevant studies, it has been decided that the oxygen-supply altitude for guaranteeing safety of construction personnel is $4500 \mathrm{~m}$. By considering classification of labor intensity and minimum oxygen consumption under different labor intensities at different altitudes given in Table 6, the oxygen-supply standard based on safety of personnel can be determined, as shown in Table 11.

Table 11. Oxygen-supply standard based on safety of construction personnel.

\begin{tabular}{ccccc}
\hline \multirow{2}{*}{ Labor Intensity } & \multicolumn{4}{c}{ Oxygen Supply (L/min) } \\
\cline { 2 - 5 } & $\mathbf{4 5 0 0} \mathbf{~}$ & $\mathbf{5 0 0 0} \mathbf{~}$ & $\mathbf{5 5 0 0} \mathbf{~}$ & $\mathbf{6 0 0 0} \mathbf{~}$ \\
\hline Very light & 0 & 0.06 & 0.13 & 0.20 \\
\hline Light & 0 & 0.12 & 0.25 & 0.39 \\
\hline Moderate & 0 & 0.18 & 0.38 & 0.59 \\
\hline Heavy & 0 & 0.24 & 0.50 & 0.78 \\
\hline Very heavy & 0 & 0.30 & 0.63 & 0.98 \\
\hline Extremely heavy & 0 & 0.36 & 0.75 & 1.18 \\
\hline
\end{tabular}

\section{Conclusions}

(1) Two standards, respectively, on the bases of labor ability and life support of construction personnel in high-altitude areas have been brought forward based on mass conservation of oxygen at sea level and in high-altitude areas, according to the impact of oxygen concentration on functions of human body during labor at sea level. An equation combining the oxygen mass conservation equation and the relationship between altitude and $\mathrm{PIO}_{2}$ of human body and oxygen concentration has been established (see Equation (3)).

(2) The altitudes for oxygen supply based on labor ability and life support are separately calculated with two methods. It is finally determined that the critical altitude at which oxygen must be supplied to construction personnel is $4500 \mathrm{~m}$, while that at which labor ability of construction personnel should be considered is $2500 \mathrm{~m}$.

(3) The joint impact of labor intensity and altitude on oxygen consumption of human body has been proposed for the first time, and the oxygen consumptions of construction personnel under different labor intensities are shown in Table 6 . The standard for oxygen supply based on labor ability is proposed, as shown in Table 10. The standard for oxygen supply based on safety is proposed, as shown in Table 11. 
Acknowledgments: This research was supported by the National Natural Science Foundation of China (NO. 51478393), Sichuan Province Science and Technology Support Program (NO. 2015GZ0244), Fundamental Research Funds for the Central Universities (NO. 2682014CX062), and Scientific Research Fund of Sichuan Provincial Education Department (NO. 14SA0251, 15SB0457).

Author Contributions: Chun Guo and Ming Nian Wang obtained the funding. Chun Guo and Tao Yan conceived the idea and the designed the study. Jian Feng $\mathrm{Xu}$ and Lu Yang collected the data. Chun Guo, Jian Feng Xu and $\mathrm{Lu}$ Yang draft the manuscript. All authors critically revised the manuscript for important intellectual content.

Conflicts of Interest: The authors declare no conflict of interest. The founding sponsors had no role in the design of the study; in the collection, analyses, or interpretation of data; in the writing of the manuscript; and in the decision to publish the results.

\section{References}

1. Deng, Y. Discussion of development trend of long tunnel construction in China. Railway Constr. Technol. 2009, 11, 72-75.

2. Sun, Y.F.; Zen, F.L. Research on the occupational hazards and their control measures of Qinghai-Tibet Railway constructors. Chin. J. Ind. Hyg. Occ. Dis. 2005, 23, 53-55.

3. Bian, S.Z.; Jin, J.; Li, Q.N.; Yu, J.; Tang, C.F.; Rao, R.S.; Yu, S.Y.; Zhao, X.H.; Qin, J.; Huang, L. Hemodynamic characteristics of high-altitude headache following acute high altitude exposure at $3700 \mathrm{~m}$ in young Chinese men. J. Headache Pain 2015, 16, 1-13. [CrossRef] [PubMed]

4. Dings, J.; Meixensberger, J.; Jäger, A.; Roosen, K. Clinical experience with 118 brain tissue oxygen partial pressure catheter probes. Neurosurgery 1998, 43, 1094-1095. [CrossRef]

5. Lv, Y.D. High altitude medicine and physiology. In Science and Technology; Translation Publishing Co. Ltd.: Tianjin, China, 1995.

6. Kawashima, A.; Kubo, K.; Kobayashi, T.; Sekiguchi, M. Hemodynamic responses to acute hypoxia, hypobaria and exercise in subjects susceptible to high-altitude pulmonary edema. J. Appl. Phys. 1989, 67, 1982-1989.

7. Lawley, J.S.; Alperin, N.; Bagci, A.M.; Lee, S.H.; Mullins, P.G.; Oliver, S.J.; Macdonald, J.H. Normobaric hypoxia and symptoms of acute mountain sickness: Elevated brain volume and intracranial hypertension. Ann. Neurol. 2014, 75, 890-898. [CrossRef] [PubMed]

8. China Traffic Construction Co., LTD. Safety Technical Specifications for Highway Engineering Construction; China Communications Press: Beijing, China, 2015.

9. Xiao, X.Z. Pathophysiology; Higher Education Press: Beijing, China, 2004.

10. Moore, L.G.; Niermeyer, S.; Zamudio, S. Human adaptation to high altitude: Regional and life-cycle perspectives. Am. J. Phys. Anthropol. 1998, 107, 25-64. [CrossRef]

11. Zhang, X.Z. Acute high altitude disease. People's Milit. Surg. 2009, 51, 638-639.

12. Zhang, L.J. High-altitude pulmonary edema. J. Med. Radiol. Technol. 2013, 36, 62.

13. André, L.G.; Xavier, L.; Monique, M.; Claude, M. High-altitude pulmonary edema at moderate altitude ( $<2400 \mathrm{~m} ; 7870 \mathrm{feet}$ )—A series of 52 patients. Chest 2003, 123, 49-53.

14. Hackett, P.H.; Roach, R.C. High-altitude cerebral edema. J. Qinghai Med. Coll. 2005, 26, 19-32. [CrossRef] [PubMed]

15. Self, D.A.; Mandella, J.G.; White, V.L.; Burian, D. Physiological determinants of human acute hypoxia Tolerance. Hypoxia 2013. Available online: http://www.faa.gov/data_research/research/ med_humanfacs/oamtechreports/2010s/media/201322.pdf (accessed on 21 December 2015).

16. Sanborn, M.R.; Edsell, M.E.; Kim, M.N. Cerebral hemodynamics at altitude effects of hyperventilation and acclimatization on cerebral blood flow and oxygenation. Wild. Environ. Med. 2015, 26, 133-141. [CrossRef] [PubMed]

17. Shi, F.K. Narrate Dalton law vividly with TP transparency. Chin. J. Chem. Edu. 1991, 5, 35-55.

18. Fang, X.B. The discussion about the relationship between air pressure and altitude height once more. J. Ankang Univ. 2005, 1, 96-97.

19. Yu, Y.Z.; Li, T.L.; Liu, Z.L. Discussions on labor sanitation and protection in high-altitude areas. Health Res. 1978, 1, 248-254.

20. Hechtman, H.B.; Reid, M.H.; Dorn, B.C.; Weisel, R.D. Indicator dilution measurements of lung volumes and alveolar air exchange during breathing. J. Clin. Investig. 1973, 52, 1215-1229. [CrossRef] [PubMed] 
21. Gilbert, R.; Auchincloss, J.H.; Kuppinger, M.; Thomas, M.V. Stability of the arterial/alveolar oxygen partial pressure ratio. Effects of low ventilation/perfusion regions. Crit. Care Med. 1979, 7, 267-272. [CrossRef] [PubMed]

22. Borland, C.D.; Cox, Y. Effect of varying alveolar oxygen partial pressure on diffusing capacity for nitric oxide and carbon monoxide, membrane diffusing capacity and lung capillary blood volume. Clin. Sci. 1991, 81, 759-765. [CrossRef] [PubMed]

23. Balykin, M.V.; Karkobatov, K.D. Systemic and organ mechanisms of the organism oxygen supply in high altitude. Ross Fiziol Zh Im IM Sechenova. 2012, 98, 127-136.

24. Liu, Y.S.; Cui, H.S.; Liu, W.H.; Feng, K.X.; Le, K.; Yu, Q.X. Research on oxygen supply technology of tunnel construction in high-altitude regions. Mining Metall. 2005, 14, 5-7.

25. Fang, R.; Yu, S.H.; Xia, C.C.; Ci, D.; Li, J.L. Research on key oxygen-supply technology of extra-long tunnel construction in high-altitude and cold regions. Railway Transp. Technol. 2014, 1, 177-179.

26. Yan, T.; Wang, M.N.; Guo, C.; Chen, H.B.; Xie, W.Q. Research on key technology of diffusing oxygen-supply of high-altitude extra-long railway tunnel. Modern Tunnel Technol. 2015. [CrossRef]

27. National Bureau of Standards of China. Classification on intensity of physical work. Available online: http:/ / baike.baidu.com/link?url=1hxkNtaCdFyqyi_SI219oBPOh9EnYu2JXfXHC7irWlE-EoL-aF5knHgzut 4UW_CR_MqUrvMLdegrEk-twARWQa (accessed on 25 August 2015).

28. Yang, L.; Wang, X.; Ma, M. Analysis on the service condition of Chinese classification on intensity of physical work - Comment on physical work load. Ind. Health Occ. Diseases 1995, 1, 38-42.

29. Zhang, S.J.; Li, J.G.; Song, C.P. Research on the Chinese classification on intensity of physical work on plateau. J. Chin. Ind. Hyg. Occ. Diseases. 1994, 12, 112-114.

30. Yu, Y.Z.; Li, T.L. Ventilation and oxygen consumption rate. Health Res. 1980, 4, 92-94.

31. Yang, X.; Liu, Y.S.; Shen, M.; Liu, W.H.; Zhang, H.; Li, Y.L.; Meng, Y. Maximum safe concentration of oxygen-enriched atmosphere in high altitude. J. Univ. Sci. Technol. 2009, 31, 1467-1471.

(C) 2015 by the authors; licensee MDPI, Basel, Switzerland. This article is an open access article distributed under the terms and conditions of the Creative Commons by Attribution (CC-BY) license (http:/ / creativecommons.org/licenses/by/4.0/). 